\title{
INFLUENCE OF ANATOMICAL FACTORS ON MAXILLARY SINUS MEMBRANE PERFORATION DURING SINUS FLOOR AUGMENTATION SURGERY
}

\section{A.M. Khorguani', A.M. Panin ${ }^{1}$, A.A. Kharlamov', A.S. Arutyunov' ${ }^{2}$, A.M. Tstsiashvili'}

\author{
${ }^{1}$ A.I.Evdokimov Moscow State Medical and Dental University, Department \\ of Surgical Dentistry, Moscow, Russia \\ ${ }^{2}$ Central Research Institute of Dentistry and Maxillofacial Surgery, \\ Moscow, Russia
}

Correspondence address:

Department of Surgical Dentistry, A.I. Evdokimov $1^{\text {st }}$ Moscow State Medical and Dental University, 4, building 2, Dolgorukovskaya street, Moscow, Russia 123006.E-mail:dr.khorguani@gmail.com, tel: +74999730450

\begin{abstract}
ABS TRACT - The Schneiderian membrane perforation is the most common intraoperative complication during the sinus floor elevation. The aim of the study was to evaluate different anatomical factors that can lead to the development of perforations and to identify significance of each of them. Those factors were: the membrane thickness, the presence of septa and the angle made by the medial and the lateral walls of the sinus. Preoperatively was analyzed CBCT data of 24 patients ( 32 sinuses) and compared them with the intraoperative data (the perforation rate within the whole groups was $34 \%$ ). The results showed that the most significant factor in the present investigation was the angle between the medial and the lateral walls (the perforation rate varies from $0 \%$ to $63 \%$ ).
\end{abstract}

KEYW ORDS - maxillary sinus, the Schneiderian membrane, perforation, sinus-lift surgery, cone-beam computer tomography.

\section{NTRODUCT ION}

The Schneiderian membrane perforation - is the most common complication of sinus lift surgery. The frequency of its occurrence varies from 11 to $56 \%$ according to literary dat [1]. The presence of perforation increases the risk of inflammatory complications by $5-10 \%$ and reduces the survival rate of implants by up to $15 \%[2,3,4]$. Also, damage to the Schneiderian membrane often leads to cicatricial changes and disruption of normal mucociliary clearance [5]. The use of Piezosurgery allows to reduce the frequency of development of this complication due to minimal traumatization of soft tissues during the formation of a bone window with lateral access and separation of
Article history:

Received 1 February 2019

Received in revised form 19 March 2019

Accepted 25 March 2019

the Schneiderian membrane [6, 7]. It is fundamental to assume that the anatomical features of the structure of the maxillary sinus may play a role in the development of this complication $[8,9,10]$.

The aim of the study was to identify the anatomical risk factors for the development of perforation of the mucous membrane of the maxillary sinus during sinus lift surgery. The following tasks were set:

1. at the preoperative stage to study the thickness of the mucous membrane, the features of the relief of the bottom of the sinuses (septa) and the angle between the anterior-lateral and medial walls of the sinus;

2. estimate the number of perforations arising intraoperatively;

3. determine the relationship between the above factors and the number of perforations.

\section{MATERIAL AND METHODS}

For the study, 24 patients were selected from whom the data of a cone-beam computed tomography and protocol data for 32 sinus-lifting operations in these patients were studied.

$$
\text { The criteria for inclusion of patients in the study }
$$
were:

1. the absence of teeth in the distal upper jaw;

2. the need for a sinus lift operation using the lateral window method;

3. performance of all operations by one surgeon. Criteria for non-inclusion:

1. the presence of violations of the structure of the osteomeatal complex;

2. the presence of pathological changes in the mucous membrane of the maxillary sinus.

\section{RESULTS}

Based on the preoperative analysis of CBCT data, the expected risk factors for perforation were:

1. thickness of the sinus mucosa, less than $1.5 \mathrm{~mm}$ in 17 cases and more than $1.5 \mathrm{~mm}$ in 15 cases (Fig. 1); 
2. the angle between the anterior-lateral and medial walls of the sinus in the area where the operation was necessary. According to this criterion, all the sinuses were divided into 3 groups: group A - with an angle of up to $30^{\circ}(\mathrm{N}=8)$; Group $\mathrm{B}$ - with an angle value from 30 to $60^{\circ}(\mathrm{N}=15)$; Group $\mathrm{C}-$ with an angle of more than $60^{\circ}$ $(\mathrm{N}=9)$ (Fig. 2);
Moreover, if the angle exceeds $60^{\circ}$, then even if there are other anatomical risk factors (thickness of the mucosa less than $1.5 \mathrm{~mm}$, the presence of septa), the likelihood of this complication is significantly reduced (Fig. 5).

\section{CONCLUSION}

When analyzing the data obtained, it was found that the angle between the anterior-lateral and medial

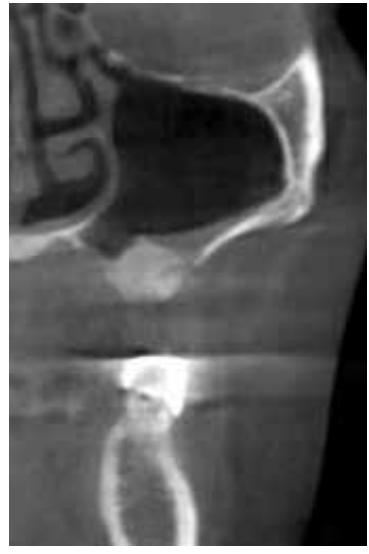

Fig.1. Khorguani Thick sinus membrane

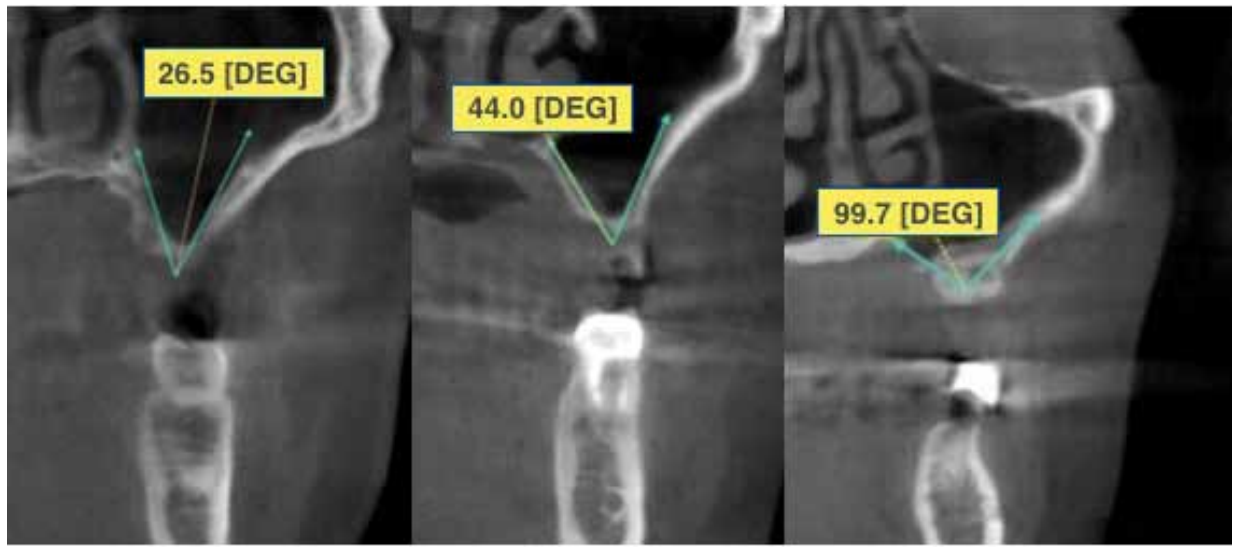

Fig. 2. Khorguani Angle degree between medial and lateral walls
3. the presence of septa in the region of the bottom of the maxillary sinus (in the course of the work, the septa was found in only one case, therefore this criterion was excluded from further research) (Fig. 3).

Analysis of the protocols of the performed operations showed that in 32 operated sinuses, perforation occurred in 11 cases (34\%) (Fig.4).

Comparison of intraoperative data with CBCT data allowed to determine that:

1. at a mucosal thickness of up to $1.5 \mathrm{~mm}$, perforation appeared in 7 cases out of 17 (41\%); with a thickness of $1.5 \mathrm{~mm}$ or more - in 4 out of 15 (27\%);

2. with the angle between the anterior-lateral and medial wall up to $30^{\circ}$ (group A), the perforation of the Schneiderian membrane occurred in 5 cases out of $8(63 \%)$; when the value is from 30 to $60^{\circ}$ (group B) - in 4 out of 15 (27\%); at a value of $60^{\circ}$ and more (group C) - in no case did the perforation occur $(0 \%)$.

\section{DISCUSSION}

The results of the study showed that most often perforation occurs at small values of the angle between the anterior-lateral and medial walls of the sinus. walls of the maxillary sinus can be a leading risk factor for the occurrence of mucosal perforation. CBCT allows to measure the angle and predict the development of perforation of the Schneiderian membrane. It is recommended to start exfoliation of the mucous membrane from the distal parts of the maxillary sinus, where the angle is at its maximum, which will reduce the tension of the membrane, and reduce the frequency of occurrence of this complication.

\section{REFERENCES}

1. ZiJderVELd SA, vaN deN BERGH, JPA, SCHULTEN EAJM, ten Bruggenkate CM. Anatomical and surgical findings and complications in 100 consecutive maxillary sinus floor elevations. J Oral Maxillofac Surg 2008; 66: 1426-38.

2. OH E, Kraut RA. Effect of Sinus Membrane Perforation on Dental Implant Integration: A Retrospective Study on 128 Patients. Implant Dent 2011 20(1):13-16.

3. Viña-Almunia J, Peñarrocha-Diago Ma, Peñarrocha-Diago M. Influence of perforation of the sinus membrane on the survival rate of implants placed after direct sinus lift. Literature update. Med Oral Patol Oral Cir Bucal. 2009 Mar 1;14 (3):E133-6.

4. Arias-Irimia O et AL. Meta-analysis of etiology of odontogenic maxillary sinusitis. Med Oral Cir Bucal. 2010 Jan 1; 15(1):e 70-3. 


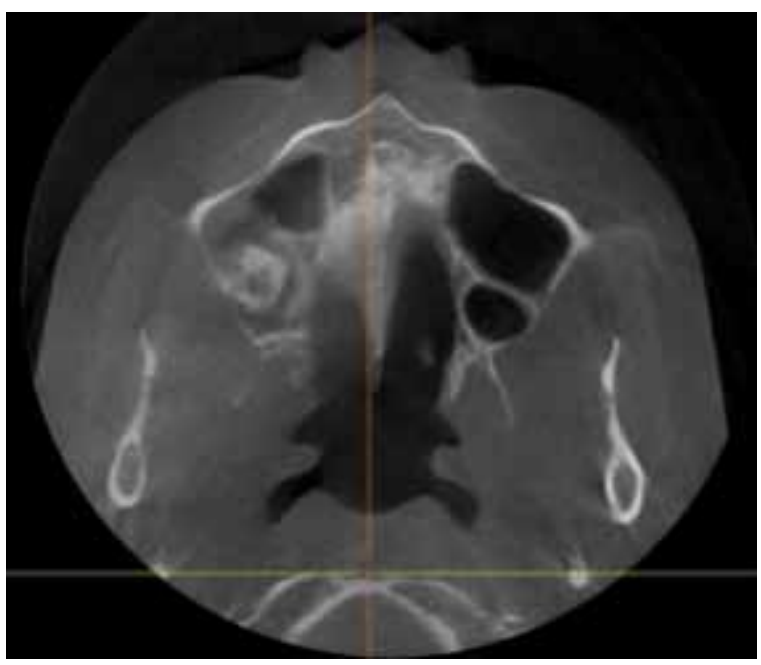

Fig.3. Khorguani Maxillary sinus septa

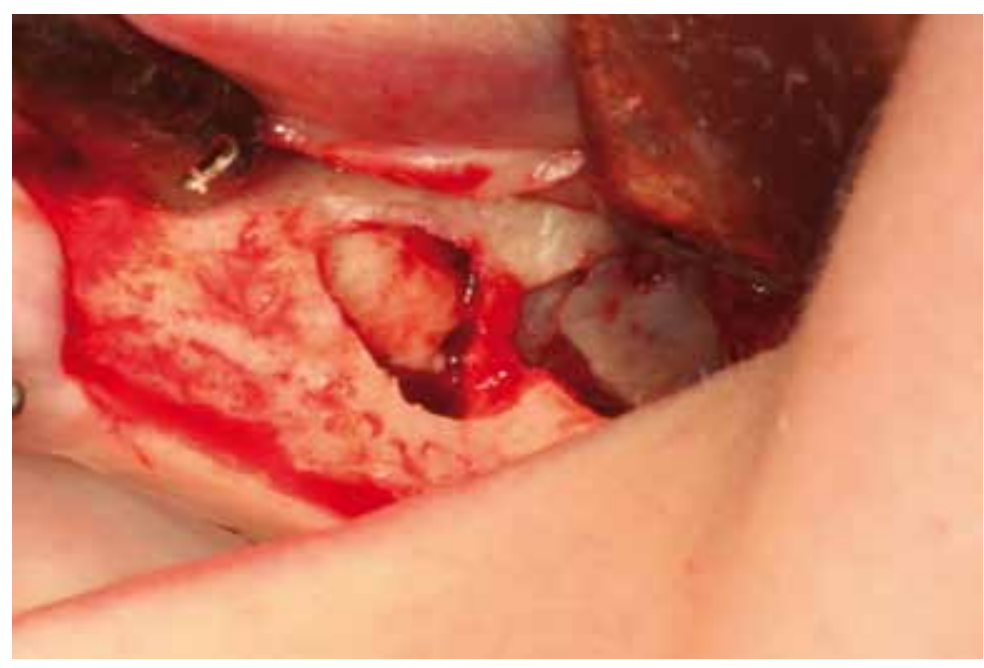

Fig.5. Khorguani Maxillary sinus septa intraoperatively

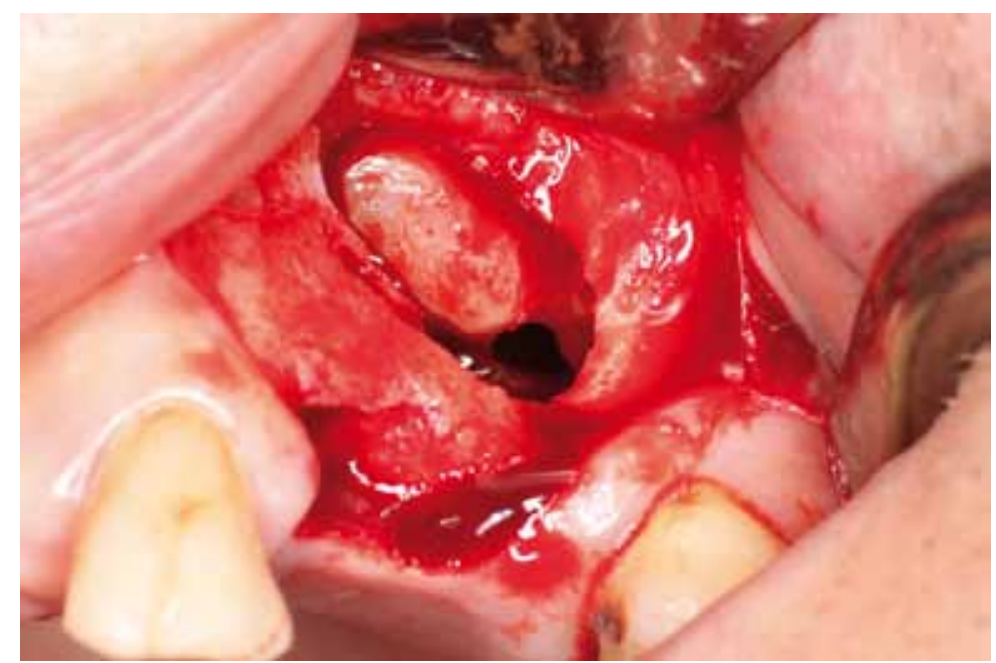

Fig.4. Khorguani Perforation of sinus membrane
5. IKEDA K, Hirano K, OShima T, Shimomura

A, Suzuki H, Sunose H, et al. Comparison of complications between endoscopic sinus surgery and Caldwell-Luc operation. Tohoku J Exp Med 1996;180:27-31.

6. Wallace SS, Mazor Z, Froum SJ, Cho S-C, TARnOw DP. Shneiderian Membrane Perforation Rate During Elevation Using Piezosurgery: Clinical Results of 100 Consecutive Cases. The International Journal of Periodontics \& Restorative Dentistry 2007 27(5):412-419.

7. Toscano NJ, Holtzclaw D, Rosen PS. The Effect of Piezoelectric Use on Open Sinus Lift Perforation: A Retrospective Evaluation of 56 Consecutively Treated Cases From Private Practices. J Periodontol $2010 \mathrm{Jan} ; 81(1): 167-171$.

8. Cho S-C, Wallace SS, Froum SJ, Tarnow DP. Influence of anatomy on Schneiderian membrane perforations during sinus elevation surgery: threedimensional analysis. Pract Proced Aesthet Dent 2001;13:160-3.

9. Monje A, Diaz KT, Aranda L, Insua A, GarciaNogales A, Wang HL. Schneiderian Membrane Thickness and Clinical Implications for Sinus Augmentation: A Systematic Review and Meta-Regression Analyses. J Periodontol. 2016 Aug;87(8):888-99.

10. Kalyvas D, Kapsalas A, Paikou S, Tsiklakis K. Thickness of the Schneiderian membrane and its correlation with anatomical structures and demographic parameters using CBCT tomography: a retrospective study. Int J Implant Dent. 2018 Oct 19;4(1):32. 